\title{
Preparation and Adsorption Properties of Polyacrylamide/Graphene Oxide Composite Aerogel
}

\author{
Yanyan Dong*, Wendan Wu*, Liping Liang*, Shuqi Tao* and Xu Meng*(**)† \\ $\mathrm{N}^{*}$ College of Textile and Garment, College of Life Science, Shaoxing University, Shaoxing, 312000, China \\ **Key Laboratory of Clean Dyeing and Finishing Technology of Zhejiang Province, Shaoxing University, \\ Shaoxing, 312000, China \\ $\dagger$ Corresponding author: Xu Meng; xumeng@usx.edu.cn
}

Nat. Env. \& Poll. Tech.

Website: www.neptjournal.com

Received: 13-07-2019

Accepted: 05-10-2019

Key Words:

Polymer;

Composite material;

Adsorption;

Aerogel

\begin{abstract}
Graphene oxide (GO) and acrylamide (AM) were polymerized and cross-linked to form a composite aerogel. The microscopic properties and thermal stability of the composite aerogel were characterized by infrared spectroscopy, thermogravimetric instrument and scanning electron microscopy. The adsorption properties of the composite aerogel were tested. The effects of temperature, GO/AM ratios, $\mathrm{pH}$ values, feed amounts, dye liquor concentrations and times on the adsorption properties of composite aerogels were investigated. The results showed that under the same experimental conditions, the more the aerogel dosage and the longer the adsorption time, the better the adsorption performance of the composite aerogel on the active yellow dye liquor; the temperature had little effect on the adsorption of the dye liquor. The gel had the greatest adsorption effect under acidic conditions. The $\mathrm{pH}$ was 0.99 , the dosage was $0.25 \mathrm{~g}$, the concentration of the dye solution was $40 \mathrm{mg} / \mathrm{L}$, and the adsorption rate reached $65.51 \%$ after adsorption for 24 hours.
\end{abstract}

\section{INTRODUCTION}

With the rapid development of textile printing and dyeing industry, large quantities of industrial wastewater which contain dyes are discharged into the water (Ali et al. 2012, Liu et al. 2017). Adsorption is a simple and low-cost method, especially suitable for printing and dyeing wastewater treatment. The key to adsorption method is to find adsorbent with low price, simple preparation and good adsorption effect (Fei et al. 2016, Mahdavinia et al. 2014).

Aerogels are composed of polymer molecules or nanoparticles that cluster together (Buerkle et al. 2009). The main component of aerogels is gas, and the periphery of them is made up of cross-linked three-dimensional network solid structures. These properties of aerogels make them to have excellent physical performance, such as porous, low-density, excellent adsorption, good light transmittance, large specific surface area and especially low thermal conductivity (Gaharwar et al. 2011, Sorour et al. 2013, Nanda et al. 2012).

$\mathrm{GO}$ is the oxidation derivative of graphene, the chemical structure of GO is roughly, and a lot of oxygen-containing active groups attach in the two-dimensional plane of GO (Akhavan et al. 2011). These reactive groups can not only make the GO have good hydrophilicity, also provide the surface functionalization of GO with many active sites (Heidarizad et al. 2016). Due to the good dispersion of GO in the water, it is difficult to achieve effective separation after adsorption through centrifugation and filtration. In practical applications, it is general that modify magnetic nanoparticles on the surface of GO or implement the solid-phase extraction of GO-based materials by immobilization. Normally, the immobilization or surface modification processes will occupy or consume some functional sites on the surface of GO, reducing the role position of target molecules in adsorption, which affect GO adsorption properties.

PAM is mainly used in flocculation, precipitation, sludge dewatering, and sewage treatment of industrial wastewater. The molecular chain of PAM contains some polar groups, which can cross-link the particles through suspended solid particles in the adsorption solution or form larger flocculates through neutralization (Pal et al. 2018, Shettigar et al. 2018, Ou et al. 2017). These accelerate the sedimentation of particles, which has an obvious effect of accelerating solution clarification.

This work based on huge application value of PAM and GO in sewage treatment, composite modified GO and PAM innovatively and prepared the polyacrylamide/GO composite aerogel. In this experiment, the adsorption properties of composite aerogel were investigated. The influencing factors on the adsorption process were explored, such as the ratio of $\mathrm{GO} / \mathrm{AM}$ in the composite, $\mathrm{pH}$, temperature, time, inventory and concentration of dye solution. 


\section{MATERIALS AND METHODS}

Chemicals and Equipment: All the chemicals and equipment were procured from standard and reputed companies.

Preparation of graphene oxide: The desired amount of grapheme $(2 \mathrm{~g})$ was added to a $500 \mathrm{~mL}$ three-necked flask containing $46 \mathrm{~mL}$ of concentrated sulfuric acid in an ice water bath. The suspension was stirred by a magnetic stirrer for $15 \mathrm{~min}$, and $6 \mathrm{~g}$ of $\mathrm{KMnO}_{4}$ was added as slowly as possible to the solution. The temperature of the solution was strictly controlled below $20^{\circ} \mathrm{C}$ during the addition. After the addition, the mixture was stirred by mechanical stirring for $2 \mathrm{~h}$ and then kept at $35^{\circ} \mathrm{C}$ for 30 minutes. The solution was diluted by $92 \mathrm{~mL}$ of DI water. After 15 minutes, a dose of $280 \mathrm{~g}$ of DI water was further added to the solution for further dilution and then $20 \mathrm{~mL} \mathrm{H}_{2} \mathrm{O}_{2}$ with a concentration of $30 \%$ was added. The reaction continued until the solution turned bright yellow. After filtration, the solid product was washed with hydrochloric acid with a concentration of $30 \%$. The $\mathrm{pH}$ of the solid product was maintained at 7.0 by washing with DI water. The product was dried to constant weight with a vacuum freeze dryer and ground into suitable fine particles to obtain a final product.

Preparation of GO/AM composite aerogel: $2 \mathrm{~g}$ of acrylamide, $0.01 \mathrm{~g}$ of azobisisobutyronitrile and $50 \mathrm{~g}$ of absolute ethanol were added into a $250 \mathrm{~mL}$ three-necked flask. Then the mixture was shaken and slightly heated to completely dissolve the acrylamide. And then $1 \mathrm{~mL}$ of diethylene glycol dimethacrylate and $0.05 \mathrm{~g}$ of anhydrous sodium carbonate was sequentially added to the vessel. The desired amount of graphene oxide $(0.01 \mathrm{~g})$ was weighed and put into $50 \mathrm{~g}$ of absolute ethanol. After the graphene oxide was sufficiently dispersed in absolute ethanol by ultrasonic vibration, it was added to the three-necked flask. Then, the mixture was mechanically stirred at $70^{\circ} \mathrm{C}$ and reacted with condensed water for three hours to obtain a solid-liquid mixture, which was subjected to vacuum filtration, and the obtained solid which was frozen in a refrigerator for $12 \mathrm{~h}$ was dried to constant weight by a vacuum freeze dryer. The dried solid was ground to obtain a polyacrylamide/graphene oxide composite aerogel.

Drawing of the reactive yellow standard curve: $0.5 \mathrm{~g}$ of reactive yellow was added into a beaker containing $50 \mathrm{~mL}$ of DI water, stirred well with a glass rod. Then the solution in beaker was poured into a volumetric flask $(500 \mathrm{~mL})$. Then solution which was made by washing the beaker multiple times with DI water was poured into the volumetric flask. The DI water was added to the volumetric flask to near the marked line and then was slowly added to the marked line with a plastic dropper. The reactive yellow stock solution with a concentration of $1000 \mathrm{mg} / \mathrm{L}$ was prepared by shaking the solution well.

$0.5 \mathrm{~mL}$ of the reactive yellow stock solution was accurately measured added into $49.5 \mathrm{~mL}$ of DI water to obtain a reactive yellow solution at the concentration of $10 \mathrm{mg} / \mathrm{L}$. The other solutions of different concentrations $(20 \mathrm{mg} / \mathrm{L}, 30$ $\mathrm{mg} / \mathrm{L}, 40 \mathrm{mg} / \mathrm{L}, 50 \mathrm{mg} / \mathrm{L}, 60 \mathrm{mg} / \mathrm{L}, 70 \mathrm{mg} / \mathrm{L}$ ) was prepared according to the same method.

The absorbance of the reactive yellow solution from 10 $\mathrm{mg} / \mathrm{L}$ to $70 \mathrm{mg} / \mathrm{L}$ was measured by UV-Vis spectrophotometer. The relationship between absorbance and concentration was calculated by a computer. The results are given in Table 1 and Fig. 1, respectively.

Adsorption performance of GO/AM composite aerogel: $11 \mathrm{~mL}$ stock solution was added to $1089 \mathrm{~mL}$ DI water to prepare reactive yellow solution at the concentration of 10 $\mathrm{mg} / \mathrm{L}$. After thoroughly stirring, $10 \mathrm{~mL}$ of the solution was taken to measure the absorbance. Then $200 \mathrm{~mL}$ of reactive yellow solution $(10 \mathrm{mg} / \mathrm{L})$ was added into $250 \mathrm{~mL}$ Erlenmeyer flask, added with $0.40 \mathrm{~g}$ of composite aerogels with different $\mathrm{GO} / \mathrm{AM}$ ratios, then sealed and placed in a gas bath thermostat for adsorption at $25^{\circ} \mathrm{C}$ and $110 \mathrm{rpm}$ for 24 hours. Then, the supernatant was filtered with a filter to measure the absorbance, and the adsorption after adsorbing was obtained according to the standard curve. The aerogel with the best adsorption performance was obtained according to the before and after comparison.

The adsorption was measured using the aerogel of best $\mathrm{GO} / \mathrm{AM}$ ratio at different $\mathrm{pH}$ to get the best $\mathrm{pH}$ for adsorption. Then the same method was used to obtain the optimal adsorption temperature and the adsorption performance in different adsorbent dosages and different solution concentrations.

\section{RESULTS AND DISCUSSION}

FTIR spectroscopy analysis: The infrared spectroscopy spectra of GO/AM composite aerogel before and after adsorption were investigated. As shown in Fig. 2, a relatively broad absorption peak appeared around $3381 \mathrm{~cm}^{-1}$, indicating that a red-shift of intermolecular or intramolecular hydrogen

Table 1: Data source of the standard curve.

\begin{tabular}{|lccccccc|}
\hline Concentration $(\mathrm{mg} / \mathrm{L})$ & 10 & 20 & 30 & 40 & 50 & 60 & 70 \\
\hline Absorbance & 0.149 & 0.305 & 0.492 & 0.66 & 0.828 & 0.981 & 1.112 \\
\hline
\end{tabular}




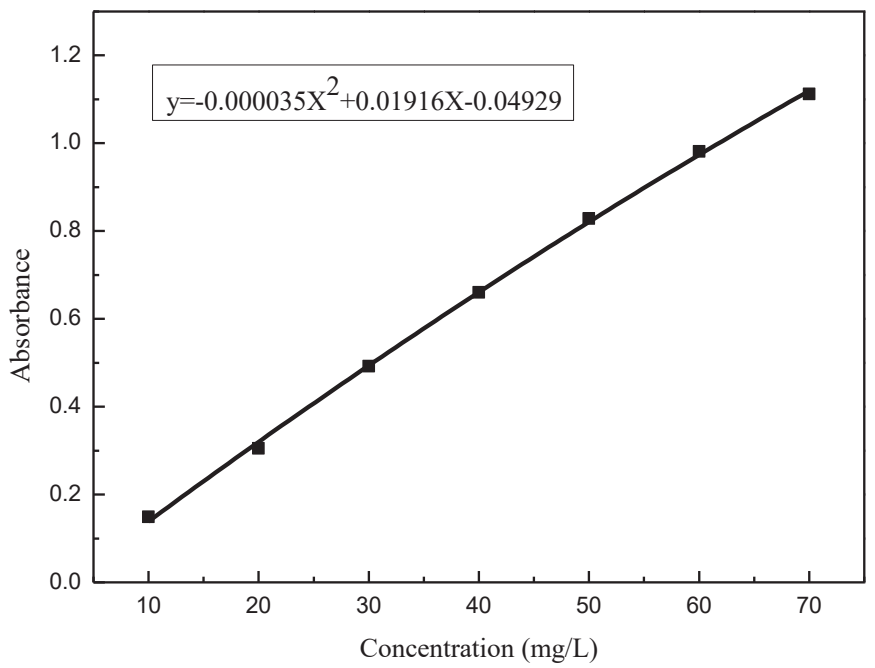

Fig.1: Standard curve of the reactive yellow.

bond occurred. The peak appeared at about $3176 \mathrm{~cm}^{-1}$ indicated that a stretching vibration of the $\mathrm{N}-\mathrm{H}$ bond occurred. The peak appeared at about $1645 \mathrm{~cm}^{-1}$ which was assigned to the $\mathrm{C}=\mathrm{C}$ vibration on the aromatic ring of the graphene oxide sheet. The absorption peak appeared at $1596 \mathrm{~cm}^{-1}$ and $1494 \mathrm{~cm}^{-1}$ could likely be assigned to the skeleton vibration of the aromatic ring. The characteristic absorption peak of $\mathrm{C}-\mathrm{O}-\mathrm{C}$ was $1132 \mathrm{~cm}^{-1}$. According to the absorption peak, the $\mathrm{GO} / \mathrm{AM}$ complex aerogel was formed successfully.

Analysis of SEM morphology: Typical scanning electron microscopic (SEM) images of GO/AM composite aerogels at different multiples before and after adsorption were shown in Fig. 3. By observing and comparing the SEM images at the same multiples, it could be seen that there were many pores on the surface of the composite aerogel before adsorption. These pores appeared because the ice had sublimated during the freeze-drying process, and the pores on the composite aerogel were advantageous to adsorb the dye. The pores on the aerogel after adsorption were greatly reduced because the aerogel adsorbed a large number of dye particles which blocked the pores in the composite aerogel.

Thermogravimetric analysis: The curve a indicated the

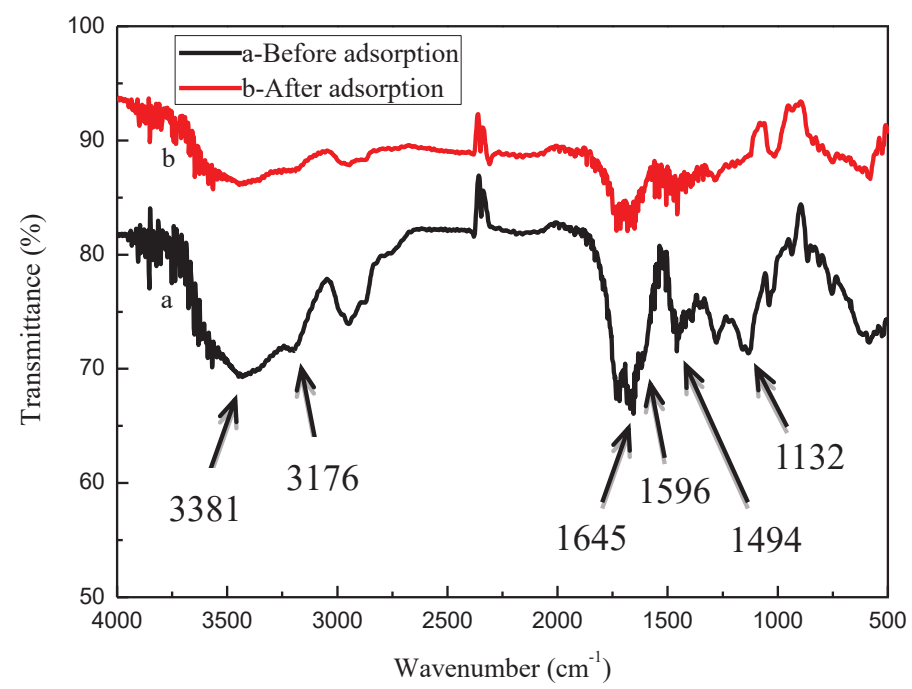

Fig. 2: Infrared spectroscopy before and after adsorption of composite aerogel. 
thermogravimetric curve before the adsorption of the $4.5 \%$ GO/AM composite aerogel, and the curve $\mathrm{b}$ indicated the thermogravimetric curve after the adsorption of the active yellow dye solution by the $4.5 \% \mathrm{GO} / \mathrm{AM}$ composite aerogel. According to Fig. 4, the weight loss before $180^{\circ} \mathrm{C}$ was assigned to the decomposition of a part of oxygen-containing functional groups and small molecular substances in the aerogel. The weight loss from about $180^{\circ} \mathrm{C}$ to $326^{\circ} \mathrm{C}$ corresponded to the decomposition of the remaining oxygen-con- taining functional groups. The weight loss from $326^{\circ} \mathrm{C}$ to $410^{\circ} \mathrm{C}$ was mainly due to the process of deamination of adjacent amide groups and formation of acyldiamine. The weight loss above $410^{\circ} \mathrm{C}$ is the process of dehydrogenation and carbon dioxide formation. The comparison of the two curves showed that the thermal stability of the adsorbed material was slightly increased because the composite aerogel adsorbed a certain amount of reactive yellow, and the thermal stability of the reactive yellow was higher than that of the
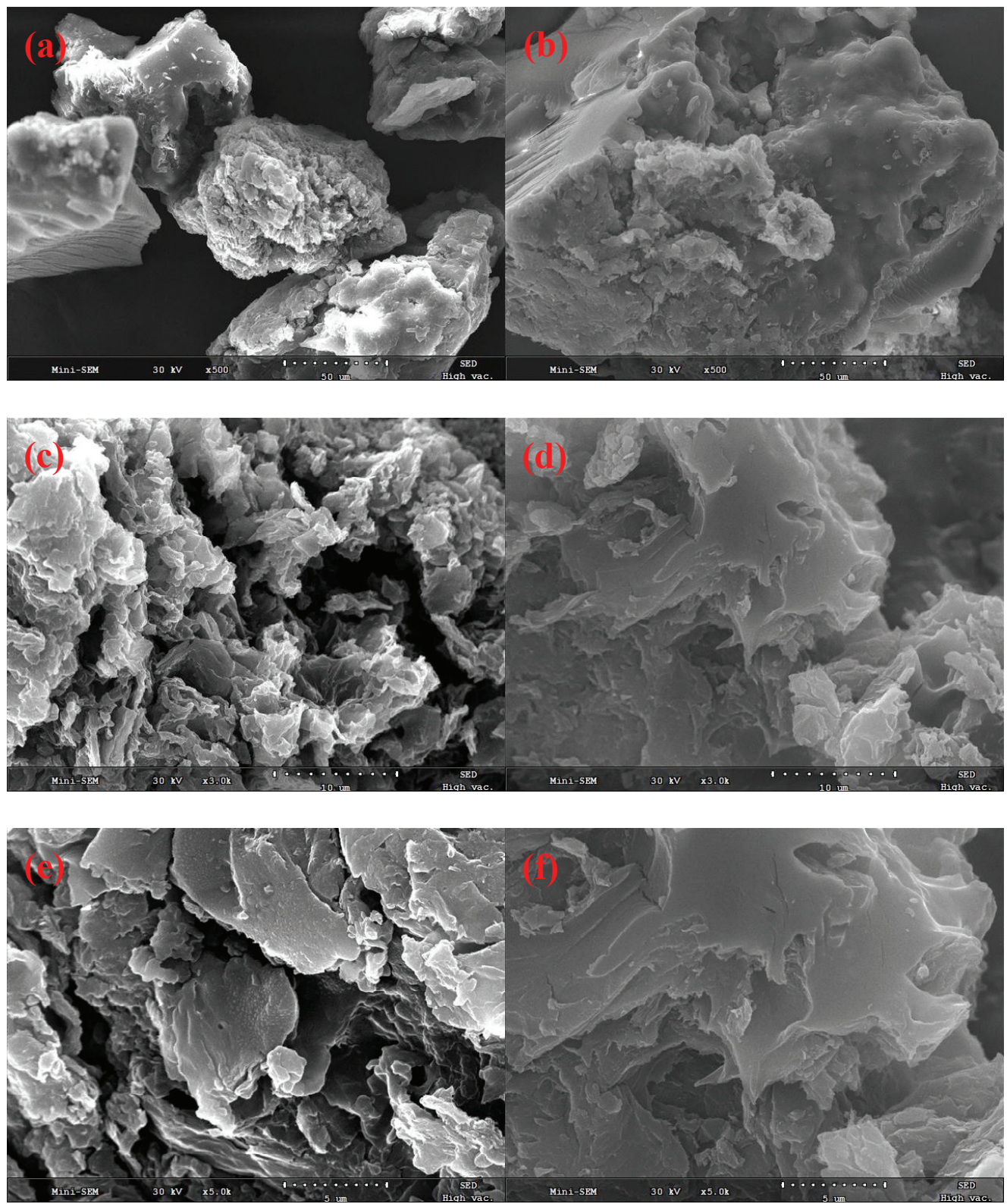

Fig. 3: a. before adsorption (500 times); b. after adsorption (500 times); c. before adsorption (3000 times); d. after adsorption (3000 times); e. before adsorption (5000 times); f. after adsorption (5000 times). 


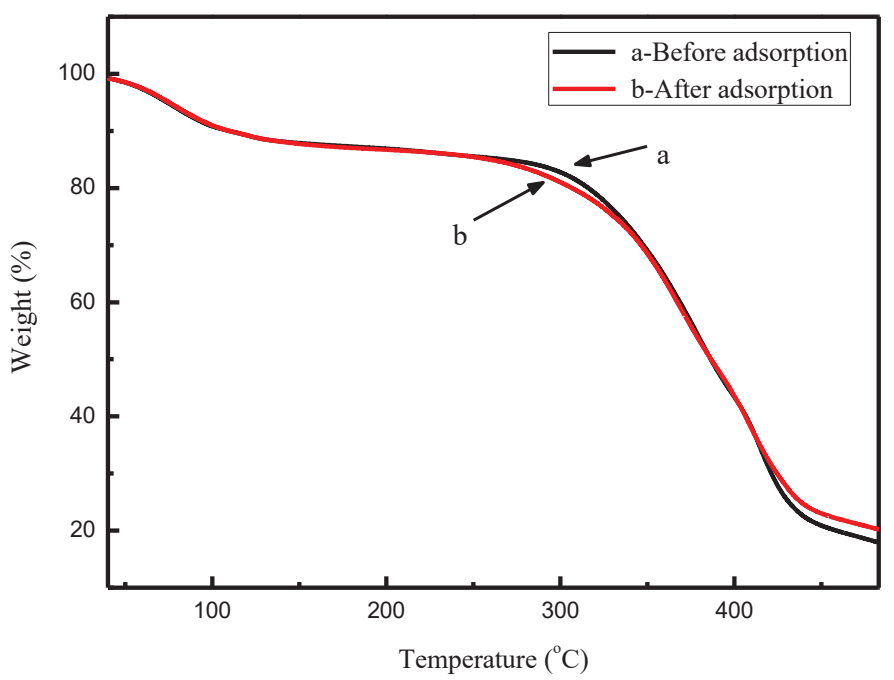

Fig. 4: Thermogravimetric diagram before and after adsorption of composite aerogel.

GO/AM composite aerogel, which caused the enhancement of the thermal stability.

Adsorption isotherm: Fig. 5 was the adsorption isotherm of the $0.5 \% \mathrm{GO} / \mathrm{AM}$ composite aerogel. As shown in Fig. 5 , as the concentration of the reactive yellow dye solution, increased from $20 \mathrm{mg} / \mathrm{L}$ to $60 \mathrm{mg} / \mathrm{L}$, the equilibrium adsorption amount of the composite aerogel increased. This was because of the initial concentration of the dye solution increased, the number of molecules of the reactive yellow dye increased too, and the diffusion driving force increased as well so that the adsorption between the composite aerogel and the reactive yellow dye was more sufficient.

Adsorption equilibrium model: Equations such as Freundlich and Langmuir could usually be used to express the adsorption equilibrium of dyes in aqueous solutions. By fitting the equations of Freundlich and Langmuir in the adsorption test data of the composite aerogel on the reactive yellow dye solution, it was found that the adsorption of the reactive yellow by the composite aerogel was suitable for fitting with the Freundlich equation. Assuming that the adsorption reaction occurred on the surface of the inhomogeneous medium, the Freundlich equation could be expressed

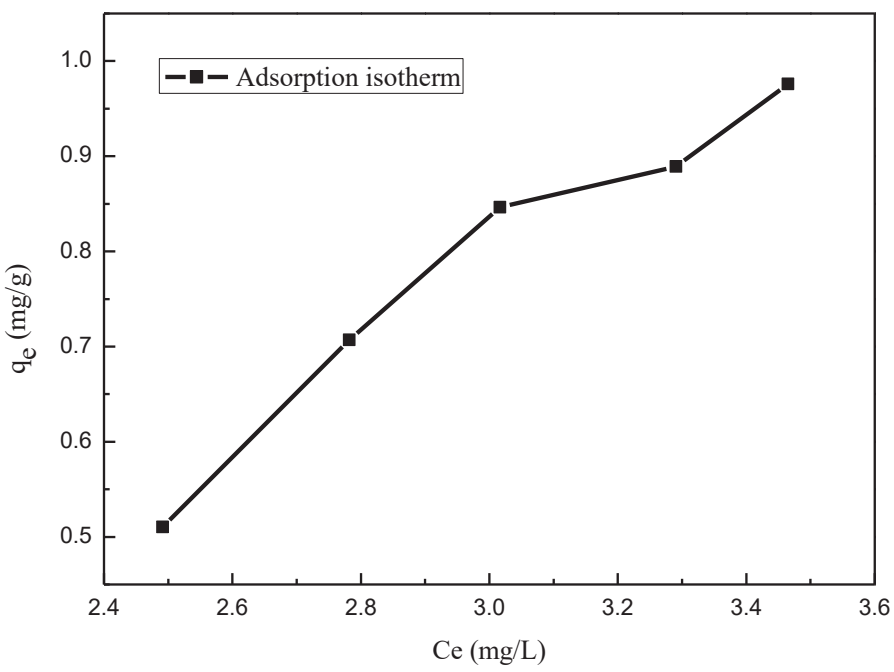

Fig. 5: Adsorption isotherm. 


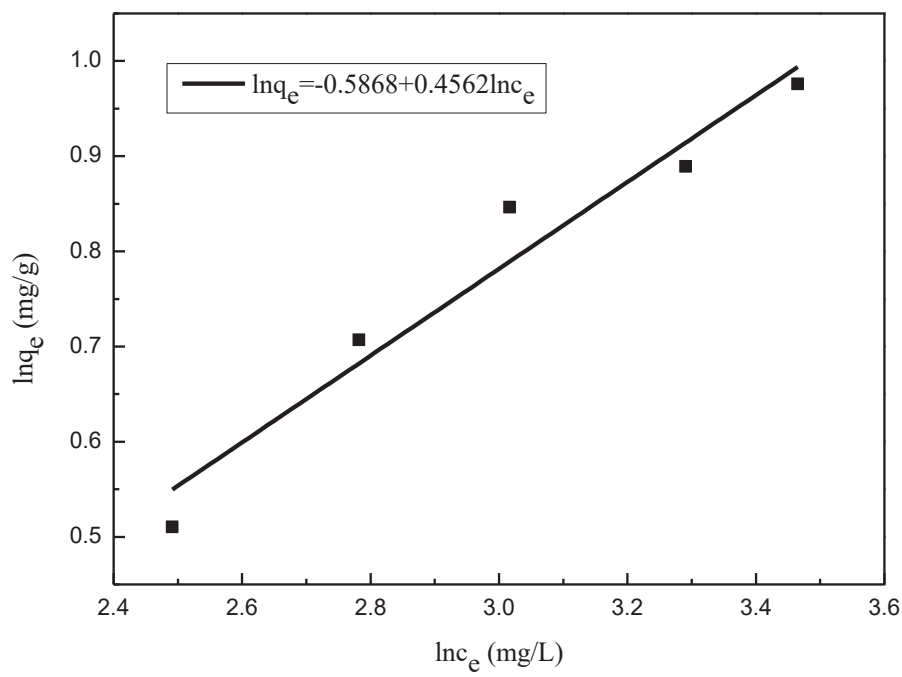

Fig. 6: Freundlich isotherm fitting line.

as $\ln \mathrm{q}_{\mathrm{e}}=\operatorname{lnq} \mathrm{F}+(1 / \mathrm{n}) \ln \mathrm{C}_{\mathrm{e}}$, where the $\mathrm{q}_{\mathrm{e}}(\mathrm{mg} / \mathrm{g})$ is the equilibrium adsorption capacity, the $\mathrm{kF}(\mathrm{L} / \mathrm{mg})$ is the constant of adsorption capacity, the $1 / \mathrm{n}$ is an empirical parameter, related to the adsorption density, the $\mathrm{C}_{\mathrm{e}}$ is the equilibrium concentration of the solution, and the values of $1 / \mathrm{n}$ and $\mathrm{kF}$ can be calculated from the linear relationship between $\operatorname{lnq}_{\mathrm{e}}$ and $\operatorname{lnC}_{\mathrm{e}}$. The fitting curve is presented in Fig. 6, and the value of $R^{2}$ is 0.9519 , which indicated that the adsorption reaction of reactive aerogel on reactive yellow occurred on the surface of the composite aerogel.

\section{Effect of different ratios of GO/AM composite aerogel}

on adsorption effects: As shown from the picture in Fig. 7, from left to right is the dye solution before adsorption (1) and the dye solution after adsorption [(2) $0.5 \% \mathrm{GO} / \mathrm{AM}$, (3) $1.5 \% \mathrm{GO} / \mathrm{AM}$, (4) $2.5 \% \mathrm{GO} / \mathrm{AM}$, (5) $3.5 \% \mathrm{GO} / \mathrm{AM}$, (6) $4.5 \% \mathrm{GO} / \mathrm{AM}]$

The adsorption parameters from left to right were the solution before adsorption and after adsorption $(0.5 \%, 1.5$ $\%, 2.5 \%, 3.5 \%, 4.5 \%$ GO: AM mass ratio). The time of adsorption was $24 \mathrm{~h}$, the adsorption temperature was $25^{\circ} \mathrm{C}$, and the adsorption $\mathrm{pH}$ was 1.5 . The amount of aerogel feed was $0.3 \mathrm{~g}$, and the reactive yellow dye solution concentration

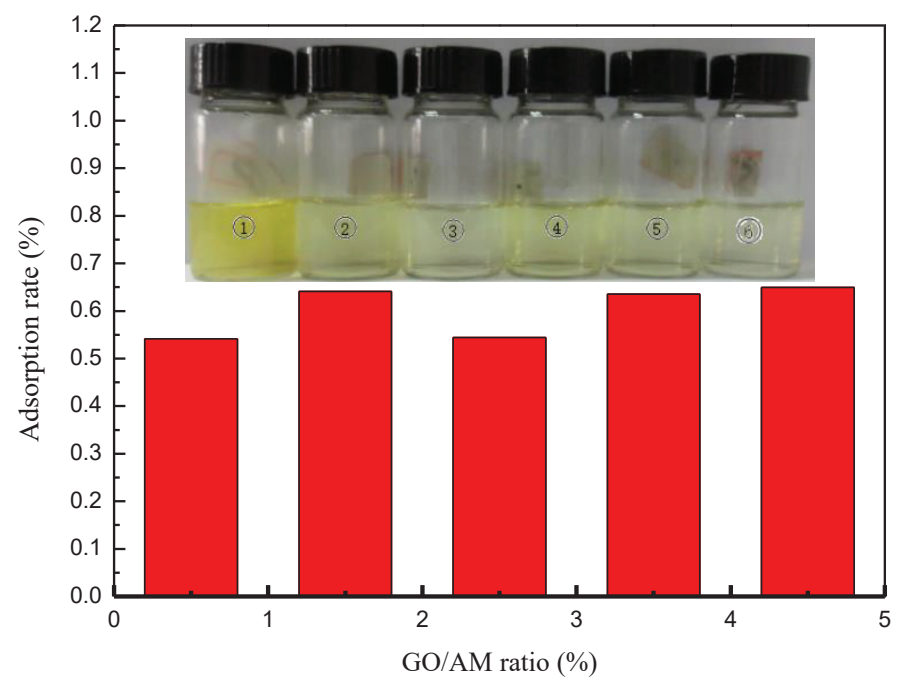

Fig. 7: Adsorption rate of reactive yellow dye by different ratios of GO/AM. 


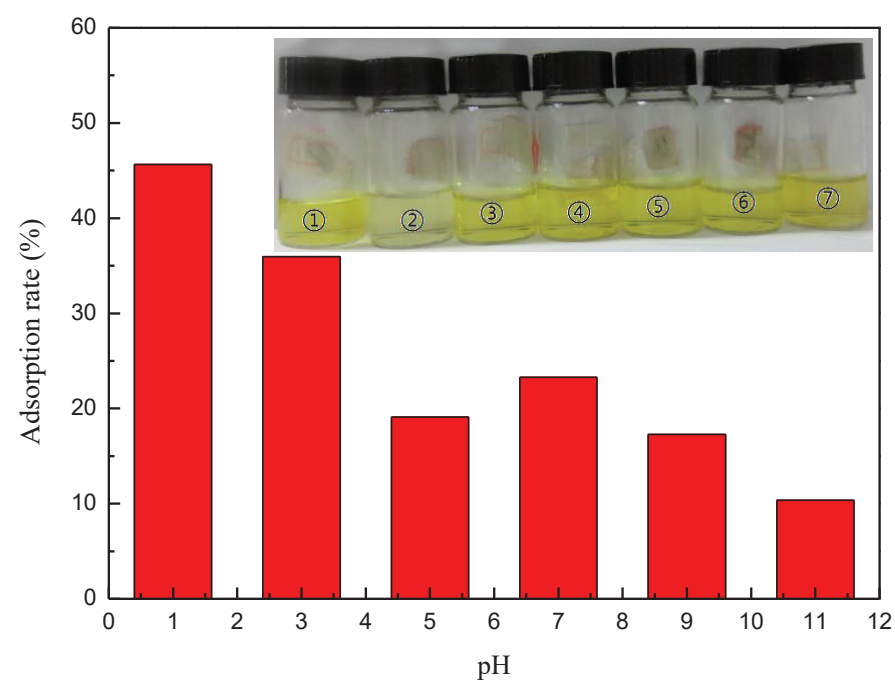

Fig. 8: Column chart of adsorption rate of different $\mathrm{pH}$.

was $20 \mathrm{mg} / \mathrm{L}$. It can be seen from Fig. 7 that the adsorption effect of aerogel tends to increase with the increasing of GO. It is because that GO contains a large number of active groups containing oxygen. And the amount of active site increases with the increasing of GO content what result in the enhancement of adsorption performance.

Effect of different pH of GO/AM composite aerogel on adsorption effects: As shown from the picture in Fig. 8, from left to right, are solution before and after adsorption with different $\mathrm{pH}$ ((1) $\mathrm{pH}=1$, (3) $\mathrm{pH}=3$, (4) $\mathrm{pH}=5$, (5) $\mathrm{pH}=7$,
(6) $\mathrm{pH}=9,(7) \mathrm{pH}=11)$. The adsorption parameters were GO: AM mass ratio with $4.5 \%$, the time of adsorption of 24 hours, and the adsorption temperature of $25^{\circ} \mathrm{C}$. The aerogel dosage was $0.15 \mathrm{~g}$, and the concentration of reactive yellow dye was $20 \mathrm{mg} / \mathrm{L}$. It can be seen from Fig. 8 that the GO/AM composite aerogel has the best adsorption effect under acidic conditions, the feed amount is $0.15 \mathrm{~g}$, and the adsorption rate can reach $45.64 \%$.

GO/AM composite aerogel adsorption effect with different feeding amount: The pictures in Fig. 9 from left to

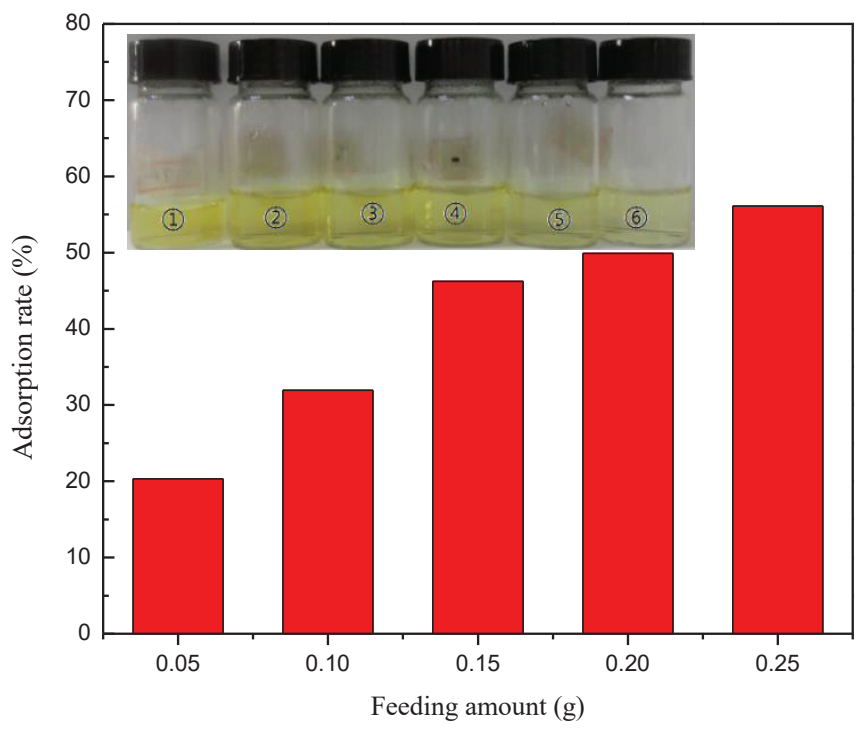

Fig. 9: Column chart of adsorption rate of different feed rates. 
right were solution before adsorption (1) and the solution of different feeds [(2) $0.05 \mathrm{~g}$, (3) $0.10 \mathrm{~g}$, (4) $0.15 \mathrm{~g}$, (5) 0.20 $\mathrm{g}$, (6) $0.25 \mathrm{~g}]$ after adsorption. Adsorption parameters: The aerogel charge amount was $0.05 \mathrm{~g}, 0.10 \mathrm{~g}, 0.15 \mathrm{~g}, 0.20 \mathrm{~g}$, $0.25 \mathrm{~g}$, and the GO: AM mass ratio was $4.5 \%$. The adsorption time was 24 hours, the adsorption temperature was $25^{\circ} \mathrm{C}$, the adsorption $\mathrm{pH}$ was 1.9 , and the concentration of the reactive yellow dye solution was $20 \mathrm{mg} / \mathrm{L}$.

According to Fig. 9, as the composite aerogel dosage increased from $0.05 \mathrm{~g}$ to $0.25 \mathrm{~g}$, the adsorption rate of the adsorbent to the reactive yellow dye solution increased from $20.33 \%$ to $56.10 \%$. This is because of the amount of adsorbent increased, the adsorbent provided more active sites and functional groups, making the adsorption reaction more sufficient, thereby increasing the adsorption rate of the aerogel to the reactive yellow dye solution.

Adsorption effect of different concentrations of dye solution: In Fig. 10, the pictures from left to right were the concentration of the reactive yellow dye solution before and after adsorption [(1) $20 \mathrm{mg} / \mathrm{L}$, (2) $30 \mathrm{mg} / \mathrm{L}$, (3) $40 \mathrm{mg} / \mathrm{L}$, (4) $50 \mathrm{mg} / \mathrm{L}$, (5) $60 \mathrm{mg} / \mathrm{L}]$. Adsorption parameters: The concentrations of reactive yellow dye solution were $20 \mathrm{mg} / \mathrm{L}, 30$ $\mathrm{mg} / \mathrm{L}, 40 \mathrm{mg} / \mathrm{L}, 50 \mathrm{mg} / \mathrm{L}$ and $60 \mathrm{mg} / \mathrm{L}$. The GO: AM mass ratio was $4.5 \%$, the adsorption time was 24 hours, the adsorption temperature was $25^{\circ} \mathrm{C}$, the adsorption $\mathrm{pH}$ was 1.9 , and the feed amount was 0.25 g. Fig. 10 and Fig. 11 show that when the concentration of the dye solution is between $20 \mathrm{mg} / \mathrm{L}$ and $60 \mathrm{mg} / \mathrm{L}$, the concentration of the dye solution has little effect on the adsorption rate.

Adsorption effect at different temperatures: In Fig. 12, the pictures from left to right were the solution before adsorption and after adsorption [(2) $10{ }^{\circ} \mathrm{C}$, (3) $20{ }^{\circ} \mathrm{C}$, (4) 30 ${ }^{\circ} \mathrm{C}$, (5) $40{ }^{\circ} \mathrm{C}$, (6) $50{ }^{\circ} \mathrm{C}$. Adsorption parameters: adsorption temperatures were $10{ }^{\circ} \mathrm{C}, 20{ }^{\circ} \mathrm{C}, 30^{\circ} \mathrm{C}, 40{ }^{\circ} \mathrm{C}$ and $50{ }^{\circ} \mathrm{C}$, GO: AM mass ratio was $4.5 \%$, adsorption time was 24 hours, adsorption temperature was $25^{\circ} \mathrm{C}$, adsorption $\mathrm{pH}$ was 1.75 , feed amount was $0.15 \mathrm{~g}$.

It can be seen from Fig. 12 that there is almost no difference in the adsorption effect of aerogel at $10^{\circ} \mathrm{C}, 20^{\circ} \mathrm{C}$, $30^{\circ} \mathrm{C}, 40^{\circ} \mathrm{C}$, and $50^{\circ} \mathrm{C}$, indicating that the temperature has little effect on the adsorption of GO/AM composite aerogel. Adsorption effect at different times: In Fig. 13, the pictures from left to right, the adsorption effects were as follows: adsorption for $0 \mathrm{~h}, 3 \mathrm{~h}, 6 \mathrm{~h}, 9 \mathrm{~h}, 12 \mathrm{~h}$, and $24 \mathrm{~h}$. Adsorption parameters: from left to right, adsorption for (1) $0 \mathrm{~h}$, (2) $3 \mathrm{~h}$, (3) $6 \mathrm{~h}$, (4) $9 \mathrm{~h}$, (5) $12 \mathrm{~h}$, (6) $24 \mathrm{~h}$. The adsorption temperature
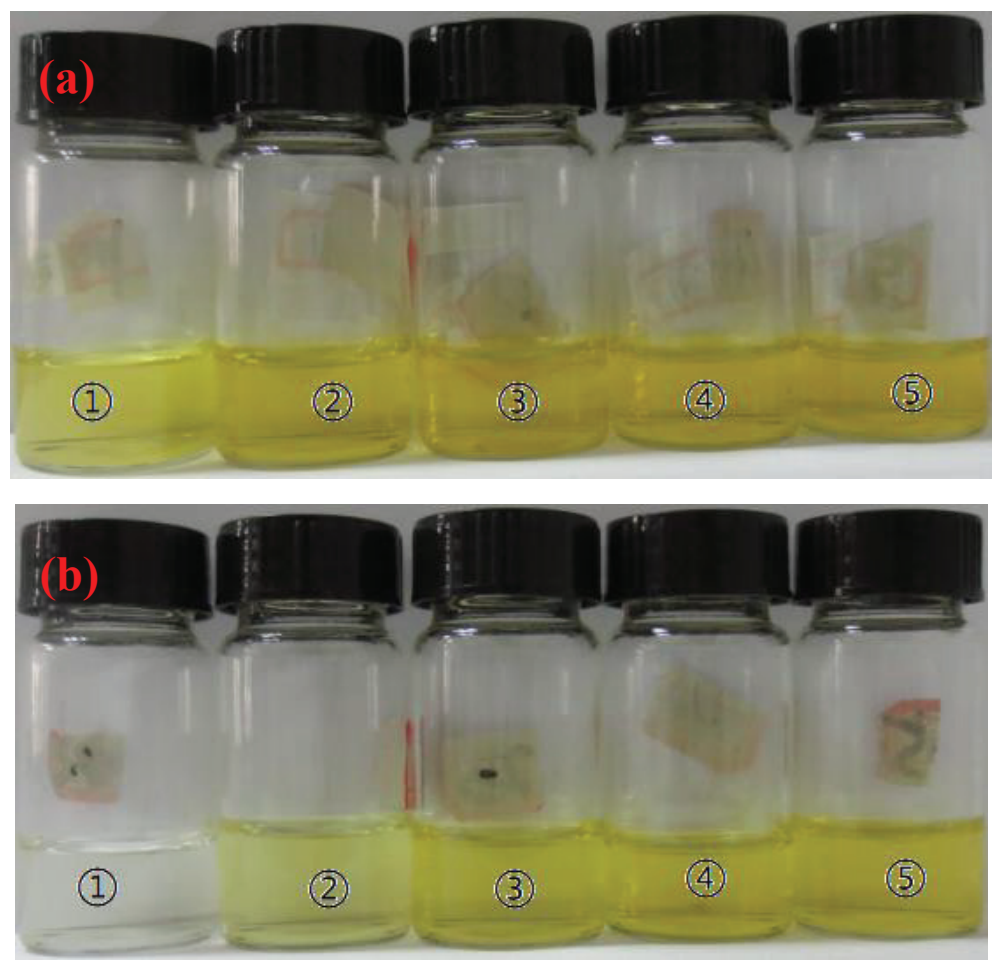

Fig.10: Different concentrations of dye solution before (a) and after (b) adsorption. 
was $25^{\circ} \mathrm{C}$, adsorption was $\mathrm{pH}=0.99$, feed amount was 0.25 $\mathrm{g}$ and the concentration of reactive yellow dye solution was $40 \mathrm{mg} / \mathrm{L}$.

It can be seen from Fig. 13, the adsorption amount of the reactive yellow dye solution by the GO/AM composite increases with time, but the increasing rate of the adsorption amount decreases with time gradually increases. The reason is that there are a large number of active sites and functional groups on the composite aerogel. At the beginning of adsorption, these active sites and functional groups participate in the adsorption reaction of the reactive yellow dye solution, so that the adsorption rate at the beginning of adsorption is faster. As the reaction proceeds, the active sites and functional groups on the composite aerogel are gradually consumed. Therefore, the adsorption amount will continue to increase, but the adsorption rate will gradually decrease.

\section{CONCLUSION}

The polymerization and crosslinking process of acrylamide are used to combine GO and AM to form a composite aerogel, which combined the polyacrylamide and graphene oxide. The prepared composite aerogel has many pores and exhib-

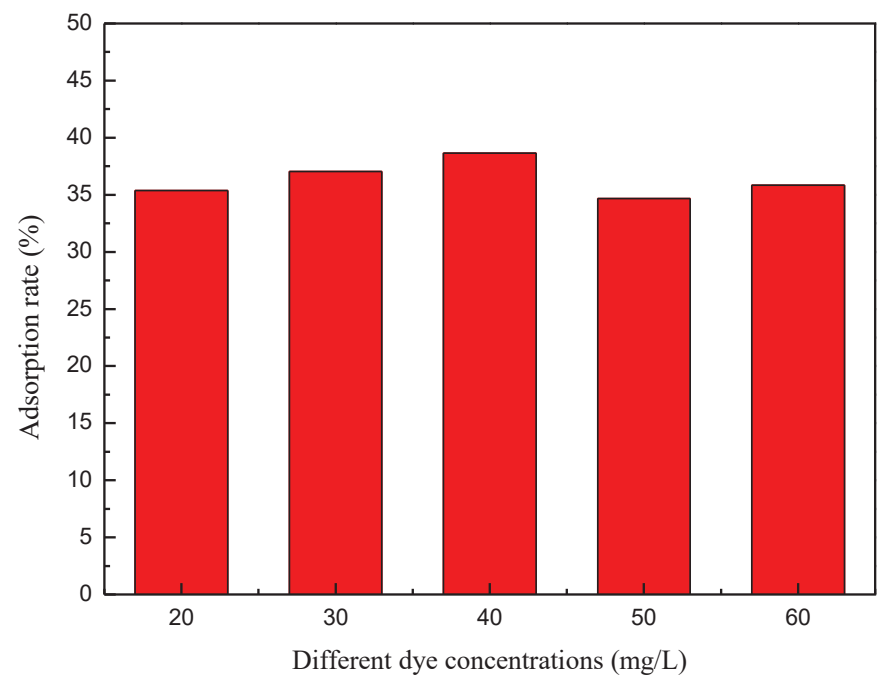

Fig. 11: Adsorption rate of different dye liquor concentrations.

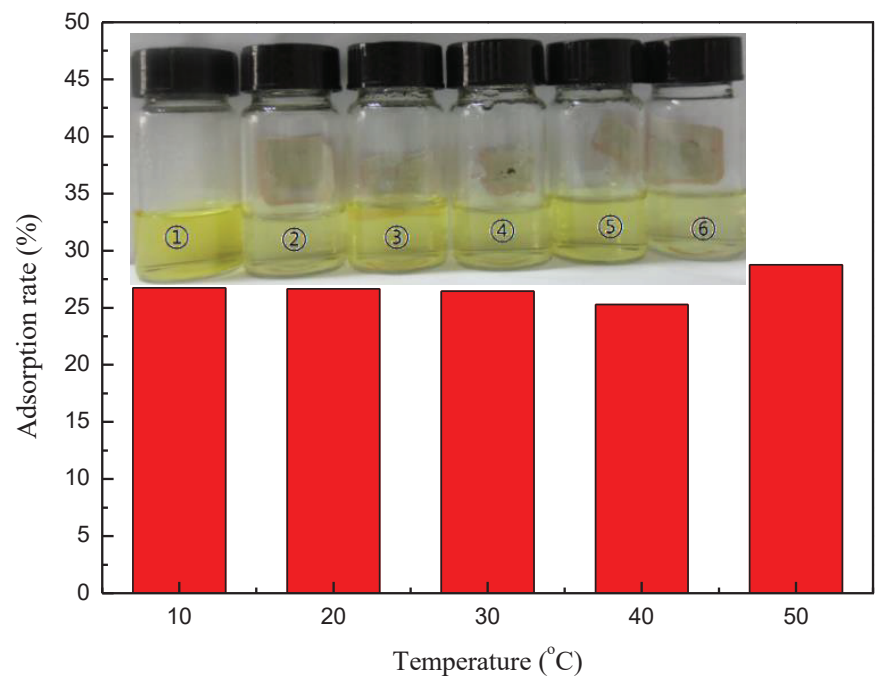

Fig. 12: Column chart of different temperature adsorption rates. 


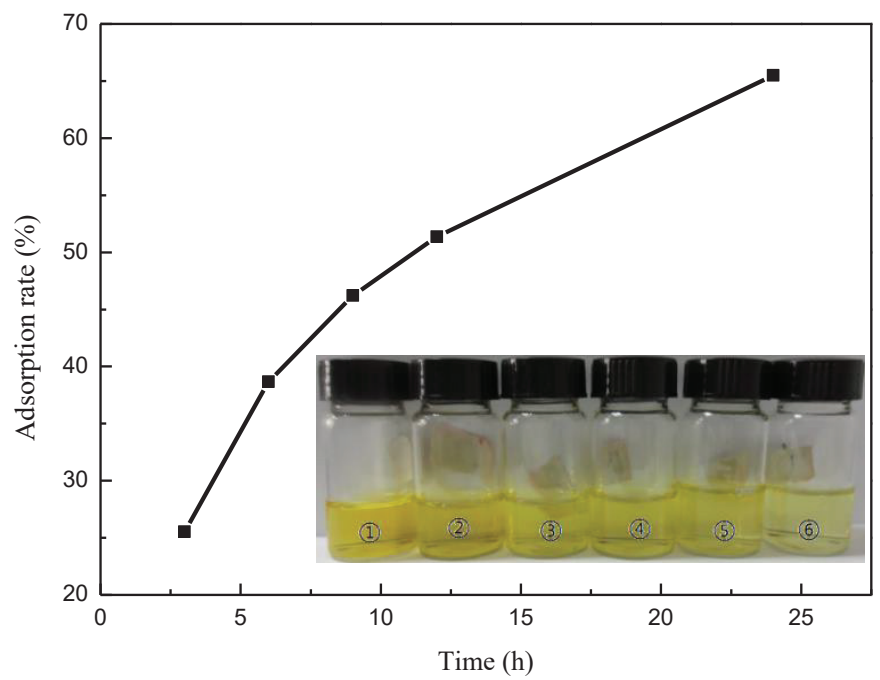

Fig. 13: Adsorption rate at different times.

its excellent adsorption performance to the reactive yellow dye solution. Through the adsorption experiment and the analysis of the adsorption results, it is concluded that $4.5 \%$ GO/AM (mass ratio) has the best adsorption performance for the reactive yellow dye solution. The optimum adsorption temperature is $50{ }^{\circ} \mathrm{C}$, and the $\mathrm{pH}$ is 1 . The adsorption effect is enhanced as the aerogel feed increased.

\section{ACKNOWLEDGEMENT}

The authors gratefully acknowledge the financial support of the National Natural Science Foundation of China (Grant No. 51703130), Zhejiang Provincial Natural Science Foundation of China (Grant No. LY18E080018), Shaoxing Public Welfare Project (Grant No. 2017B70042), and the International Science and Technology Cooperation Project of Shaoxing University (Grant No. 2019LGGH1004).

\section{REFERENCES}

Akhavan, O. 2011. Photocatalytic reduction of graphene oxides hybridized by $\mathrm{ZnO}$ nanoparticles in ethanol. Carbon, 49: 11-18.

Ali, I. 2012. New generation adsorbents for water treatment. Chemical Reviews, 112: 5073-5091.

Buerkle, L.E., Li, Z., Jamieson, A.M. and Rowan, S.J. 2009. Tailoring the properties of guanosine-based supramolecular hydrogels. Langmuir, 25: $8833-8840$.

Fei, P., Wang, Q., Zhong, M. and Su, B. 2016. Preparation and adsorption properties of enhanced magnetic zinc ferrite-reduced graphene oxide nanocomposites via a facile one-pot solvothermal method. Journal of
Alloys and Compounds, 685: 411-417.

Gaharwar, A.K., Dammu, S.A., Canter, J.M., Wu, C.J. and Schmidt, G. 2011. Highly extensible, tough, and elastomeric nanocomposite hydrogels from poly(ethylene glycol) and hydroxyapatite nanoparticles. Biomacromolecules, 12: 1641-1650.

Heidarizad, M. and engör, S.S. 2016. Synthesis of graphene oxide/magnesium oxide nanocomposites with high-rate adsorption of methylene blue. Journal of Molecular Liquids, 224: 607-617.

Liu, C., Liu, H., Xu, A., Tang, K., Huang, Y. and Lu, C. 2017. In situ reduced and assembled three-dimensional graphene aerogel for efficient dye removal. Journal of Alloys and Compounds, 714: 522-529.

Mahdavinia, G.R., Iravani, S., Zoroufi, S. and Hosseinzadeh, H. 2014. Magnetic and $\mathrm{K}+$-cross -linkedkappa-carrageenan nanocomposite beads and adsorption of crystal violet. Iranian Polymer Journal, 23: 335-344.

Nanda, J. and Banerjee, A. 2012. -Amino acid containing proteolitically stable dipeptide based hydrogels: encapsulation and sustained release of some important biomolecules at physiological $\mathrm{pH}$ and temperature. Soft Matter, 8: 3380-3386.

Ou, K., Dong, X., Qin, C., Ji, X. and He, J. 2017. Properties and toughening mechanisms of PVA/PAM double-network hydrogels prepared by freeze-thawing and anneal-swelling. Materials Science and Engineering: C, 77: 1017-1026.

Pal, P., Pandey, J.P. and Sen, G. 2018. Synthesis and study of hydrolyzed polyacrylamide grafted polyvinyl pyrrolidone (Hyd.PVP-g-PAM) as flocculant for removal of nanoparticles from aqueous system. Materials Science and Engineering: B, 236-237: 32-42.

Shettigar, R.R., Misra, N.M. and Patel, K. 2018. CTAB grafted PAM gel and its application in drilling fluid. Journal of Petroleum Science and Engineering, 160: 129-135.

Sorour, M., El-Sayed, M., Moneem, N.A.E., Talaat, H.A., Shalaan, H. and Marsafy, S.E. 2013. Characterization of hydrogel synthesized from natural polysaccharides blend grafted acrylamide using microwave (MW) and ultraviolet (UV) techniques. Starch-Stärke, 65: 172-178. 